Discourse and Communication for Sustainable Education, vol. 7, no. 1, pp. 68-81, 2016

\title{
Perceived Affordances, Tensions, and Complementarities in the Physical and Digital Environments Frequented by Future Teachers
}

\author{
Diane Pruneau, Jackie Kerry, Viktor Freiman, \\ Joanne Langis and Mohamed Bizid \\ Université de Moncton, Canada
}

\begin{abstract}
Is future teachers' contact with the physical environment significant enough for them to choose to educate their students about sustainability? These digital natives stand out from previous generations by their way of living. The research based on grounded theory was aimed at understanding future teachers' relationships with physical and technological environments. The analysis of interviews, with Moncton and Montreal teacher education students, reveals that future teachers maintain a sporadic relation to the natural environment. They are still conscious that nature provides them calmness, rejuvenation and beauty. The Internet offers them distraction, social affiliation, personalized information, and facilitates their tasks and contact with the World. Future teachers are critical and cautious in their use of ICT but are however not much involved in the environmental cause. The research emphasizes the need to work on future teachers' relationship to the physical environment with outdoor activities to get to know, appreciate, analyze and improve the natural and urban environments.
\end{abstract}

Keywords: teacher education, relationships with ICT, relationships with environment, education for sustainability

Many changes occur every day in the environments that shape us, inspire us, or put us in danger. Climate change, demographic movements, economic globalization, exploitation of new energy sources, and urban development modify environments in unpredictable ways. However, on a smaller scale, a movement toward sustainability is currently on the rise, as seen through various local alternatives: Conservation Design (Arendt, 1996), Transition Communities (Hopkins, 2008), Ecological Cities (Register, 2006), restoring biodiversity (Fuller et al., 2010), assisted migrations (McLachlan, Hellmann, \& Schwartz, 2007), etc. This movement toward sustainability gives hope for the future of our planet, as long as it brings together a large number of citizens, among which are teachers who have the power to transmit to their pupils healthy, critical, and creative practices.

However, are future teachers conscious of beneficial or uncertain and harmful events and changes that occur where they live? Is their bond with the natural environment 
strong enough to want to share with their pupils a tightly knit relationship with nature? Pre-service teachers (future teachers), likened to digital natives because of their age (Oblinger \& Oblinger, 2005), make heavy use of information and communications technologies (ICT) and are different from previous generations because of the way they live, think, work, and learn (Lardellier \& Bryon-Portet, 2010). Does intensive use of ICT by young adults distance them from physical environments? Our study sought to document the relationships of future primary school teachers with physical and digital environments, and to identify what meaning these two environments have for them. Our study aspired to answer the following questions: What environments do future teachers frequent? What do they do on Internet, in nature, and in human-built settings? What needs do these environments meet? Are they aware of what happens in these environments? Do tensions and complementarities exist between the physical and digital environments visited by these future teachers?

In this article, the authors discuss a study on the relationships future primary school teachers have with physical and digital environments. Our participants came from two Canadian universities: the Université de Moncton in New Brunswick and the Université du Québec in Montreal. We summarize the physical and digital environments they frequented, the needs these settings met, and we discuss the tensions and complementarities perceived in both types of environments as well as between them. After describing the methodology and presenting the results, we conclude by making recommendations for future teacher training in education for sustainability.

\section{Relationships with Physical Environments}

Place attachment often gives rise to the desire of protecting specific environments and to share one's enthusiasm with other people. The concepts of place attachment (Proshansky, Fabian, \& Kaminoff, 1983), ecological identity (Thomashow, 1995), environmental sensitivity (Pruneau, 1995), and community identity (Hummon, 1992) describe various aspects of a privileged relationship with the natural or human-built environment. Place attachment is among the factors that encourage people's involvement in environmental action (Chawla, 2006). Chow and Healey (2008) define it as a complex and multidimensional phenomenon that includes various aspects of one's connection to a place, including emotions, knowledge, behaviours, and actions relative to said place. Meaningful experiences in natural or human-built environments and the positive influence of close relations lead to a close relationship with the biophysical environment or the community (Arnold, Cohen, \& Warner, 2009). People become attached to places, among others, because of their affordances: what these environments can offer them (Gibson, 1977). The more a place offers opportunities for comfort, intimacy, safety, serenity, or friendly ties, the greater the attachment (Rollero \& De Piccoli, 2010). With respect to the affordances of the natural environment, Pruneau, Gravel, and Ouattara (2002) find that adolescents view nature as a place to relax, think, marvel at, play, dream, and learn. Finally, Cuba and Hummon (1993) note that people's involvement in actions to improve an environment contributes to their relationship with that environment.

However, in recent decades, anthropologists have observed a gradual decrease in the quality of human relationships with the biophysical environment and the community. Malmberg (1992) describes this change in terms of loss of identity, low awareness of 
space and time, forgotten pace of life, and weakening of the sense of territory. He explains this loss of community and ecological identity by the disappearance of natural wilderness and the fast-paced urban life. We face the extinction of experience, that is, a less direct and less frequent contact with phenomena and actors from the place of belonging. Most people have less regular exposure to colours, forms, sounds, and the magic of rich and vibrant landscapes. This social phenomenon may be at the root of apathy and lack of responsibility for the environment. However we know very little on the current quality of relationships between young adults, particularly future teachers, with their physical environment.

\section{Relationships with Digital Environments}

Research on young adults' digital activities is also embryonic. Internet is now viewed as an environment in which people can live, learn, develop, and socialize (Tapscott, 1999). The social world of future teachers includes physical and virtual environments, their real and online lives completing one another (Larsen \& Ryberg, 2011). Internet shapes young adults' personal identity because they use ICT on a daily basis for communication, entertainment, or information purposes (Martinovic \& Freiman, 2011). Technology, accused by some but celebrated and made less alarming by others, has become a need.

Young people share with their social networks their preferences, creations, games, opinions, and emotions (Larsen \& Ryberg, 2011). Social networks, which need a considerable daily investment in time, are an ever available source of human contact and support for these youths (Yang \& Brown, 2013), particularly for young women (Junco, 2013). Connected, young people influence one another by sharing experiences and ideas, or by making their experiences and ideas available to others on Internet (MargitayBecht \& Herrera, 2012). Young people's search for social interaction drives them to communicate with a diverse audience and exposes them to a range of ideas and cultural differences, while also making them feel socially included (Dorman, 2000). Young people are part of interest groups related to their activities in real life: sports, artistic production, or cultural community (Margitay-Becht \& Herrera, 2012).

Increased access to information reinforces their autonomy and their critical skills. Worried about freedom of expression, young people have strong opinions (Tapscott, 1999) and are very decisive (Oblinger \& Oblinger, 2005). They have also developed multitasking abilities (Boubée, 2011), claiming that such abilities are necessary in order to accomplish everything that must be done within the available time (Barnes, Marateo, $\&$ Ferris, 2007). With little tolerance for texts and conferences, they prefer short visual explanations, interactive multimedia, 3D environments, and animations (Oblinger, 2008). Eager for stimulation, they prefer active learning, thus showing themselves to be kinaesthetic and experimental (Pletka, 2007). Still little known, the digital experience of young adults has, however, negative aspects: cyber dependence, cyber harassment, information and stimuli overload, manipulation of values through the transmission and repetition of biased information, and reduced face-to-face communication skills (Feiertag \& Berge, 2008). 


\section{Methodology}

In order to gradually explore in depth future teachers' relationships with digital and physical environments, we chose the methodological approach known as grounded theory (Glaser, 2007). Participant observation with individual and group interviews was used to progressively model future teachers' relationships with their various environments. To keep researchers from taking position against or for ICT, we did the inventory of the three researchers' personal biases at the beginning of the study. Participant observation aimed to immerse us in the digital environments frequented by young adults (Facebook, blogs, etc.). To this end, the main investigator used Facebook for a year to understand the pros and cons. In 2013, we carried out two individual interviews to begin understanding what students experienced in both environments. The interviews included 12 volunteer students (11 women and 1 man) from the Bachelor of Primary Education Program at the Université de Moncton and 14 volunteer students (10 women and 4 men) from the same program, but at the Université du Québec in Montreal. The students represented their cohorts' diversity, coming from urban and rural backgrounds (though mainly rural). One of the interviews tackled the digital environments visited and the other dealt with physical environments.

Here are examples of questions from the interview guide for digital environments:

If you don't mind, I'd like to talk about your day yesterday. Where did you go online? Choose an activity that you did. What was it? What were you thinking about? How did you feel? Do you go there often? Please explain. What is it in this place that satisfies you? Where will you bring your pupils with technology? Are you involved in a collective action?

Here are examples of questions from the interview guide for physical environments:

$$
\begin{aligned}
& \text { Yesterday, you say that you went... Can you recall what was happening around } \\
& \text { you? What were you doing there? Were you doing something else? Can you } \\
& \text { recall what you were thinking? Do you want to talk to me about it? Do you } \\
& \text { find it pleasant to be in this place? Please explain. Do you go there often? } \\
& \text { Please explain. }
\end{aligned}
$$

We analyzed thematically (Paillé \& Mucchielli, 2008) the transcripts from the individual interviews in Moncton and Montreal to outline our first understanding of future teachers' relationship with both environments: three researchers independently read the corpus, identified and described the themes, and then consulted one another. The analysis mainly drew from the theory of affordances (perceived advantages of the environments; Gibson, 1977). Tables were thus prepared to highlight what places the students visited; their activities in these places; as well as the perceived emotions and affordances in these places. To get an idea of the importance of the various emerging themes, we linked the number of students to each theme.

Next, to give meaning to the observations accumulated, we carried out two group interviews (one on digital environments and the other on physical environments) with 10 volunteer students from a compulsory course on science didactics at the Université de Moncton. With a PowerPoint presentation showing our first results, the participants in the group interviews were asked to give their opinion on the validity of the results from the individual interviews and to comment and complete these results. The students' 
comments during the group interviews were added to the result tables to explain and illustrate them. Finally, we prepared topic trees to synthesize the results.

Later, to further confirm the results obtained, we conducted a group interview with 10 volunteer students from a course in environmental education at the Universite du Québec in Montreal. In order to avoid influencing the participating students' responses, we did a group interview that was modified to use open-ended questions. Here are a few examples: When you want to amuse yourself, to what physical and/or digital place do you go? When you want to create something, where do you go? Do you sometimes use ICT out in nature? Do you take advantage of physical places in ICT? During the interview, the comments of the students from Montreal confirmed the previous results and were used mainly to complete and illustrate the elements compiled in the topic trees. However, our open-ended questions regarding the complementarities perceived between the physical and digital environments brought out new elements that led to new results.

\section{Affordances of Digital Environments for Future Teachers}

People visit digital places on a daily basis repeatedly and for long periods of time. The places most frequented by future teachers are the following: Facebook, Internet via Google, YouTube, Pinterest, Skype (or Facetime), Hashtag, and Snapchat. Some digital places can be personalized: we constantly go back because we appreciate them.

The results of this study on Facebook affordances are in line with recent results by Tosun (2012), Bicen and Cavus (2011), and Doğruer, Menevis, and Eyyam (2011) regarding university students' online networking. Facebook, still popular and frequented during the day by our participants, was used to keep up with the news (friends and events), look at photos and videos, participate in thematic groups (work and leisure), organize social meetings, communicate with people both near and far, comment on other people's posts, and play in group games. Facebook was given the following affordances: sharing achievements, good times, and nice pictures; planning activities with friends; increasing contact with various people; getting attention and encouragement (number of Likes); helping one another with homework and life in general; getting support to make decisions; remembering good memories; accessing leisure and relieving boredom; getting information on strangers. Facebook fascinated because of its availability, speed (no need to travel), ease of access, and the variety it offers. Facebook provided emotions: enjoyment, frustration, anger, curiosity, etc.

Internet through Google was used for research; to find personalized information; to get directions; to plan trips and outings; to look for new ideas; to access information unavailable close by; to meet people, to search for music and movies; to browse; to shop and make financial transactions. The following affordances were attributed to Internet: helping with work and projects (speed of access and variety of information); assisting with writing (spelling); offering a source of enjoyment; answering personal needs and interest; offering a way to escape daily life and offsetting solitude.

YouTube was used for watching informative or popular videos, and listening to music. It was perceived as a place to find entertainment, get information, learn how to execute a task, listen to songs, comment on movies, or be known as an artist. As for Pinterest, it was used to find suggestions for pedagogical activities or ideas related to one's interests: recipes, clothes, etc. It represented inspiration and excitement for the 
new things found there. Skype or Facetime were environments in which people could meet face-to-face, mainly used with friends and family members living at a distance. They were attributed the function of accessing the non-verbal aspect of conversations. While hashtags were used to quickly find information, Snapchat was used to instantly share daily moments with friends.

The topic trees in Figures 1 to 4 show authors' understanding of future teachers' relationships with digital environments. These figures show that ICT meet the needs of contemporary life: the need to quickly accomplish a number of tasks; the need for enjoyment, inclusion, and access to the global world. In Figure 1, for example, we see that ICT offered answers to operational and performance needs in a fast-paced society in which there is an excess of tasks to accomplish. ICT helped rapidly execute various tasks (search in a dictionary, buy tickets to a show, etc.), consult a network of friends, look for pedagogical information or ideas, make financial transactions, and use online geographical maps.

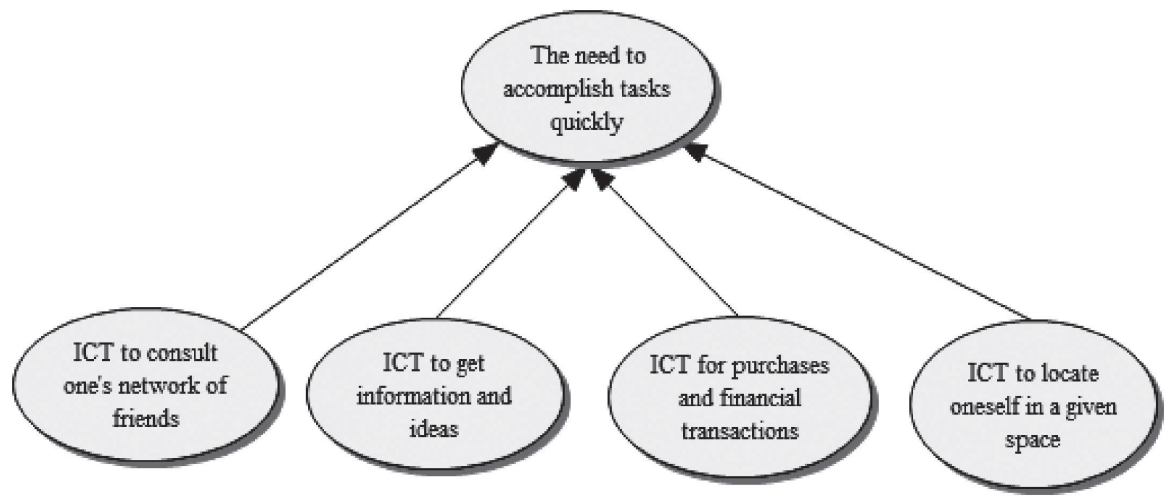

Figure 1. ICT to answer the needs of a fast-paced life

In addition, Figure 2 shows that ICT stimulated emotions and sensations, and were sources of enjoyment and adventure. For our participants, it was pleasant to meet new people with ICT, to look at many things or images made to kindle curiosity, to find things that corresponded to personal interests, to use ICT rather than traditional and costlier media like television or movie theatres, and to play games.

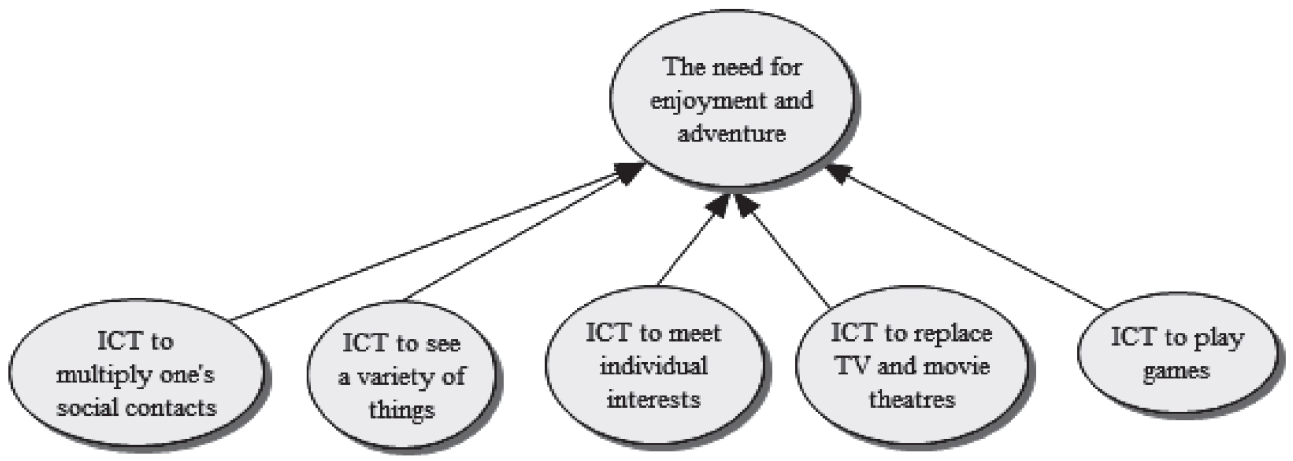

Figure 2. ICT to meet the need for enjoyment and adventure 
Figure 3 shows the need for social inclusion expressed by our participants. As with the studies by Akyildiz and Argan (2012) and Nadkarni and Hofmann (2011), ICT were used by our participants to feel like they belonged to social groups, present positive aspects of themselves, counter solitude, make new friends, stay in touch, quickly communicate their experiences, organize social meetings, and sometimes solve conflicts without direct confrontation.

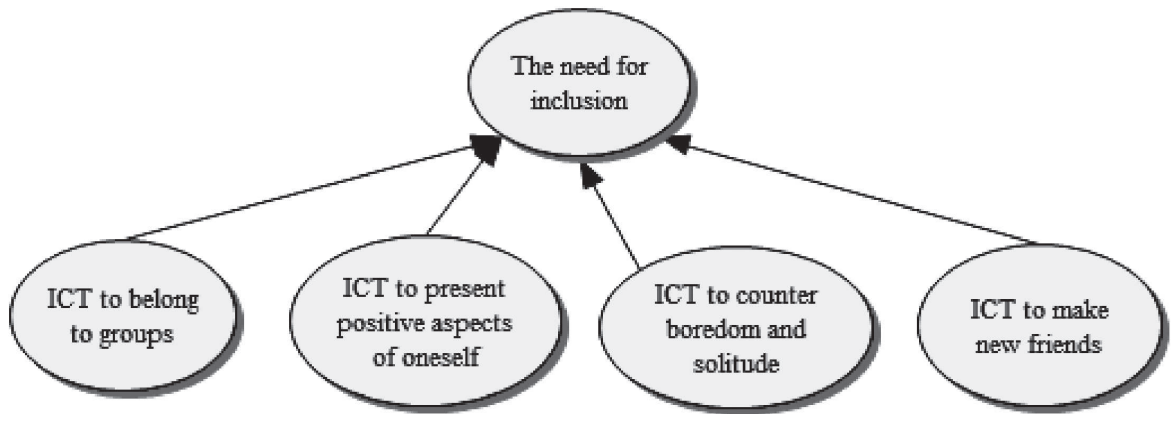

Figure 3. ICT to meet the need for inclusion

Figure 4 shows future teachers' need to participate in a global world without geographical limits. Our participants dreamed of travelling and getting in contact with other cultures. ICT met these needs by ensuring contact with landscapes, opinions, and other cultures.

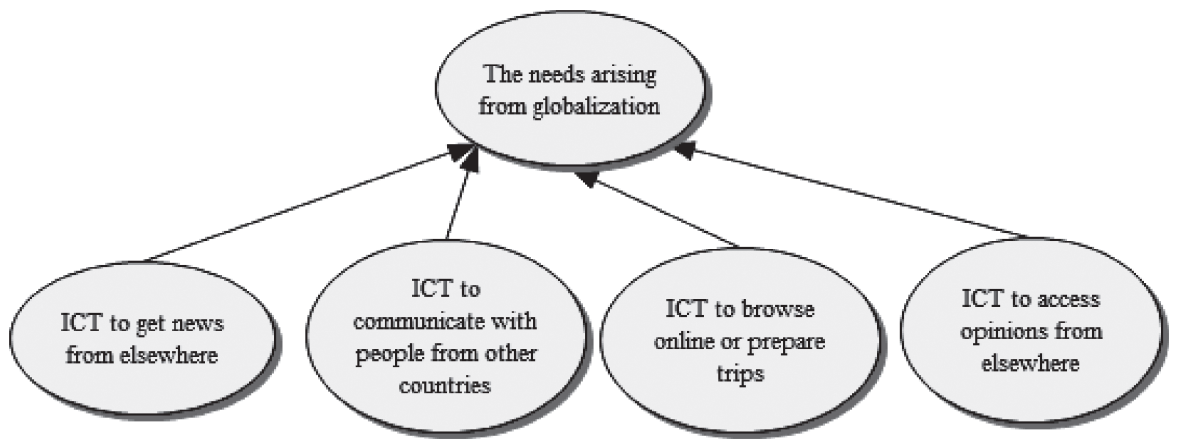

Figure 4. ICT to meet the needs arising from globalization

Finally, according to our participants, ICT were not used to create (products, ideas, etc.). The students claimed to tend to initially search for ideas on Internet that they sometimes used as found and sometimes enhanced or personalized them. ICT were rarely used to get involved in environmental actions. Indeed, the environment is considered more as a problem than as an opportunity. Except for a few more environmentally conscious participants, the environment was associated with work rather than a commitment to improve the world. 


\section{Affordances of the Physical Environment for Future Teachers}

Physical environments, excluding places of work and study, were visited more sporadically than digital environments, according to what time was available, what season it was, and access to low-cost means of transportation. Here are the physical environments most visited by future teachers in decreasing order: nature and natural parks, shopping centres, homes of friends, sports centres, restaurants/cafés/bars, and movie theatres.

In natural parks, future teachers, particularly those who did sports, did physical activities (cycling, climbing, etc.) or spent time outdoors (camping, picnicking, fruit picking, etc.). They took walks alone, with family members or with their dog, often on trails they knew well. They also listened to music or took pictures. They claimed to frequent natural areas to stay in shape or healthy; maintain family relationships; contemplate nature (which change with the seasons); seek out quiet, calm, and relaxation (putting distance between them and their worries); think about themselves; plan for the future; take a break from this fast-paced world and ICT; let new ideas grow or remember their childhood memories (nostalgia).

Figure 5 shows that the natural environment met the need to get away from our fast-paced society, to find calm, to contemplate, and to reconnect with oneself. Future teachers claimed to still be connected with the natural environment and conscious of its benefits despite the fact that they did not visit regularly and only increased during the summer.

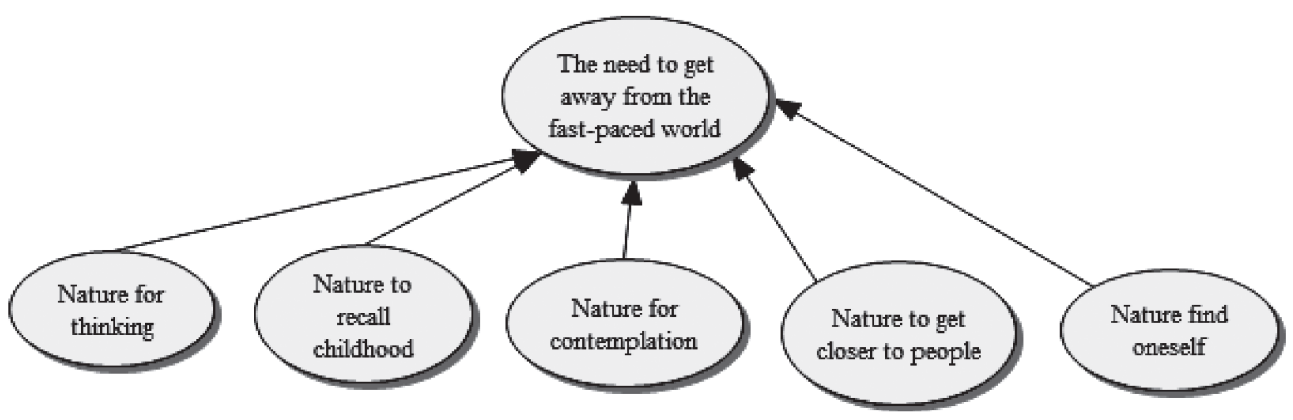

Figure 5. Nature's response to the need to get away from the fast-paced world

In shopping centres, future teachers walked (alone or with friends) or made purchases. They visited these centres to counter boredom, take their minds off things, see something new, or meet people. At friends' places, participants danced, played games (board and video), talked, worked, watched TV programs, or prepared food together. The affordances associated with visiting friends were getting news and spending quality time together. Sports centres were used to stay in shape, forget one's worries, take advantage of physical activities (mood, self-esteem, energy), meet people (widen one's social network), push their physical limits, or spend time alone. In cafés, bars, and restaurants, future teachers worked alone or in groups, met with friends, ate, and listened to music. Such places were linked to closeness with friends, eating specific or new foods, and an ambiance conducive to work. 


\section{Tension Experienced Within and In-Between Digital and Physical Environments}

Future teachers spoke of feeling many tensions within and in-between the digital and physical environments they frequented. In general, they explained that their life was excessively fast-paced with an overload of tasks to accomplish, whether for work, studies, or family. They felt overly active, forced to increase the profitability of their time, multitask, and be successful in each of their social roles. They always felt concerned with doing something. Sylvie, a participant, expressed this general tension as follows: It's as if we always have something to do, or stuff that has yet to be done, things that should be furthered, and so on.

On the one hand, Internet represented for them a wonderful tool that was always accessible and made it possible to quickly carry out a number of tasks. It instantly met their needs and gave them a feeling of efficiency. Participants expressed the following feelings: "The moment you have an idea, it's instantaneous, you can check right away" (Maryse, admiration); "You have the time to do many things simultaneously and better fill your day" (France). However, among future teachers, although advantageous, increased use of ICT and multitasking sometimes caused feelings of fatigue, saturation, and the desire to control their own technological activities. Gisele, a participant, expressed this kind of feeling as follows: "I think that it's possible not to notice that we spend so much time on it. There is always so much new information coming at you so quickly, you can look at Facebook and in 5 minutes you have news. You scroll back up and there are already 10 new posts. So it's easy to get caught up and stay there." When the students spent long moments on Internet, they had the impression of "losing their time, of not doing anything significant" (Marc).

Students' relationship with Facebook illustrates well the tension experienced between the website's social usefulness and its limitations regarding how it encourages people to meet in an anonymous environment and the dependencies it favours. Facebook was acknowledged as a facilitator of social contacts, but the future teachers were more and more cautious and critical about how they used it. Several were conscious that today's society forced them to use Facebook: "I open it at least once a day. If you don't, you're not up to date, you miss invitations, and you can't function" (Maryse). Several tried to control the time spent and what they posted on Facebook.

Although there were less of them in the natural environment, tensions were still present. When in this environment, some students fear for their personal safety or worry about missing news or telephone calls. A few of them also feel like they are wasting time they could otherwise use to accomplish tasks.

Regarding the tensions experienced between the digital and physical world, most future teachers were conscious that spending time in nature and small cafés can be good for them, but they blamed the fact that they did not have enough time to get there. They claimed to spend too much time in digital settings, which reduced the time they had to travel to a city park or a café.

\section{Complementarities Between Digital and Physical Environments}

According to the participants of this study, the digital and physical environments complemented each other in various ways. The digital environment mainly awakened feelings whereas the physical environment encouraged one to act (participate and move). 
The digital environment provoked hyperactivity, while the physical environment brought rest. Online interpersonal communication was chiefly utilitarian, whereas meeting people in person promoted more in-depth conversations and establishing real connections. ICT were also used to share photos and impressions from the physical world. ICT were useful to look for information regarding things that were encountered in natural or human-built settings.

\section{Discussion}

In seeking to answer the questions asked in this study, one can say that future teachers visited digital environments by obligation to accomplish tasks, for enjoyment, to socialize, and through their interest in a globalized and open world. Digital environments were rich in emotions, cognition, and socialization. Several future teachers were increasingly conscious and critical of the advantages and limitations of digital environments, and "tried" to adopt reflective practices in such settings. It was nevertheless difficult to know to what extent they actually controlled the time spent in digital environments and what they did there.

Physical settings like natural parks and cafés or restaurants were still visited, but in specific conditions: if time and finances allowed. While digital environments were mainly associated with stimulation (enjoyment, surprise, curiosity) or quickly accomplishing tasks, natural environments were associated with calm, recharging one's batteries, and contemplation. Other physical settings, such as shopping centres or sports centres and friends' homes had many uses: social gatherings and enjoyment. Direct social relationships were still sought after. It appeared, however, that the value given to the natural environment was becoming less marked and was not top of mind. They visited this environment during their childhood, they still believed it was good for them, but it seemed that it took effort to actually get outside. However, athletic students were still enthusiastically inclined to visit natural settings.

Tensions and complementarities emerged between the physical and digital environments visited. Future teachers claimed to want to go outside or to social places more often, but the digital environments-which seemed to meet their needs to quickly accomplish tasks and keep them connected in order to socialize and satisfy their interestsreduced the time they would otherwise have had to go to parks and cafés. Digital environments added to visits in the physical world by enabling participants to share meaningful experiences acquired in nature or in other countries.

\section{Conclusion}

This study does not allow to make gratuitous claims, such as Future teachers do not go outside and no longer have contact with the natural environment or with friends. The results are less clear-cut than that. Future teachers visited digital environments for many reasons that made it possible for them to function, be organized, and enjoy themselves in our current society. Some students were more conscious than others of the benefits of the natural environment, physical activities, and direct social contact. These made efforts to disconnect from Internet and go to places they believed would let them rest, move, or share joys and sorrows with friends. However, commitment to the environ- 
ment in community actions and awareness of a movement dedicated to the ecological design of the environment were practically non-existent among our participants.

These findings open the door to a hypothesis: future teachers' relationships with the physical environment may be in decline. If this is the case, it is essential to take them outside during their university studies. Fieldtrips could remind them of the benefits of natural settings. Moreover, Puk and Stibbards in Alvarez-Garcia et al., (2015) found a lack of understanding of core concepts about how natural systems work and the impact of social systems on natural systems in pre-service teachers. Fieldtrips in nature and in the built environment could gradually build future teachers' ecological literacy. Fieldtrips in nature and in the built environment could gradually build future teachers' ecological literacy.

According to Zecha (2013), who studied German and Spanish adolescents' experiences in nature, it might be proven that nature experiences may positively affect environmental knowledge, attitudes and actions. At least, future teachers could be more conscious of beneficial or uncertain and harmful events and changes that occur in the places where they live.

It would also be pertinent to have pre-service teachers participate in community environmental actions to demonstrate the advantages of this type of action when developing social relationships and self-esteem. Participating in a local community action could contribute to building their community identity. With respect to digital settings, since they rarely used ICT to create, they should be encouraged and taught to use various technologies in view of generating ideas.

Furthermore, critical discussions during classes could help students think about the environments they will choose to visit in relation to their health goals. As proposed by Iliško, Skrinda and Mičule (2014), teacher students should be invited to elaborate preferable scenarios for their personal individual future, including their goals, plans and strategies for getting there. What kind of activities will they choose to get involved in, to reach sustainable happiness? O'Brien (2013) defines sustainable happiness as a happiness that contributes to individual, community or global wellness without exploiting other people, the environment or future generations. What will they do to become more sustainably happy? Will they engage in regular physical activities? In what physical and technological places? Will they nourish their social networks and how and where will they do this? What kind of things will they create and for what use? Which great and noble cause will they get involved in? They could also create these kinds of scenarios for their community.

Further studies should be carried out to understand the relationships members of the generations after that of our participants will have with digital and physical environments. Indeed, the research participants claimed to be worried about younger students who have not had as many opportunities to play in nature even though they may have lived in the countryside. Regarding technologies, research should be continued on future teachers' activities with ICT considering the participants' gender, personality, ethnic background, and marital status.

Recent studies by McAndrew and Jeong (2012) and Seidman (2013) on university students' use of Facebook are beginning to provide some information on the subject. Similarly, it would be relevant to compare the physical environments visited by future teachers who display or do not display an interest for doing sports. 


\section{References}

Alvarez, P., \& Vega, P. (2004). Formacion inicial del profesorado en educacion ambiental [Environmental education in pre-service teacher training]. Revista Biocenosis [Journal Biocenosis], 18(1-2), 66-71.

Álvarez-García, O., Sureda-Negre, J. \& Comas-Forgas, R. (2015). Environmental education in pre-service teacher training: A literature review of existing evidence. Journal of Teacher Education for Sustainability, 17(1), 72-85.

Arendt, R. (1996). Conservation design for subdivision: A practical guide for creating open space networks. Washington: Island Press.

Akyildiz, M. \& Argan, M. (2012). Using online social networking: Students' purposes of Facebook usage at the University of Turkey. Journal of Technology Research, 3(1), 3-11.

Arnold, H. E., Cohen, F. G., \& Warner, A. (2009). Youth and environmental action: Perspectives of young environmental leaders on their formative influences. The Journal of Environmental Education, 40(3), 27-36.

Barnes, K., Marateo, R. C., \& Ferris, P. S. (2007). Teaching and learning with the Net Generation. Innovate Journal of Online Education, 3.

Bicen, H. \& Cavus, N. (2011). Social network sites usage habits of undergraduate students: Case study of Facebook. Procedia - Social and Behavioral Sciences, 28, 943-947.

Boubée, N. (2011). Caractériser les pratiques informationnelles des jeunes: Les problèmes laissés ouverts par les deux conceptions. "Natifs" et "naïfs" numériques. [Characterizing the information practices of young people: The problems left open by the two designs. "Native" and "naïve" digital]. Retrieved April 1, 2016, from http://www.cndp.fr/savoirscdi/fileadmin/fichiers_auteurs/Actes/Rennes_2011/NBRencontresSavoirsCDI-oct2011.pdf

Chawla, L. (2006). Research methods to investigate significant life experiences: Review and recommendations. Environmental Education Research, 12, 359-374.

Chow, K. \& Healey, M. (2008). Place attachment and place identity: First year undergraduates making the transition to the university. Journal of Environmental Psychology, 28, 362-372.

Cuba, L. \& Hummon, D. M. (1993). A place to call home: Identification with dwelling, community and region. The Sociological Quarterly, 34, 111-131.

Dorman, S. M. (2000). Implications of growing up digital. Review of Tapscott's growing up digital. The Journal of School Health, 70, 420-422.

Doğruer, N., Meneviş, I., \& Eyyam, R. (2011). What is the motivation for using Facebook? Procedia - Social and Behavioral Sciences, 15, 2642-2646.

Gibson, J. J. (1977). The theory of affordances. In R. Shaw and J. Bransford (Eds.), Perceiving, acting and knowing (pp. 142-159). Hillsdale, N.J.: Erlbaum.

Feiertag, J. \& Berge, Z. L. (2008). Training generation N: How educators should approach the Net Generation. Education + Training, 50, 457-464.

Fuller, R. A., McDonald-Madden, E., Wilson, K. A., Carwardine, J., Grantham, H. S., Watson, J. E. M., Klein, C. J., Green, D. C., \& Possingham, H. P. (2010). Replacing underperforming protected areas achieves better conservation outcomes. Nature, 466, 365-367.

Gibson, J. J. (1977). The theory of affordances. In R. Shaw and J. Bransford (Eds.), Perceiving, acting and knowing (pp. 142-159). Hillsdale, N.J.: Erlbaum. 
Glaser, B. G. (2007). Doing formal grounded theory: A proposal. Mill Valley, CA: Sociology Press.

Hopkins, R. (2008). The Transition handbook: From oil dependency to local resilience. Cambridge, UK: Green Books.

Hummon, D. M. (1992). Community attachment. In I. Altman and S. M. Low (Eds.), Place attachment (pp. 253-278). New York: Plenum Press.

Iliško, D., Skrinda, A. \& Mičule, I. (2014). Envisioning the future: Bachelor's and Masters' degree students' perspectives. Journal of Teacher Education for Sustainability, 16(2), 88-102.

Junco, R. (2013). Comparing actual and self-reported measures of Facebook use. Computers in Human Behavior, 29, 626-631.

Lardellier, P. \& Bryon-Portet, C. (2010). Ego 2.0. Quelques considérations théoriques sur l'identité et les relations à l'ère des réseaux [Some theoretical considerations about identity and relationships in the network age] Les Cahiers du Numériques, $1,13-34$.

Larsen, M. C. \& Ryberg, T. (2011). Youth and online social networking: From local experiences to public discourse. In E. Dunkels, G.-M. Franberg, and C. Hallgren (Eds.), Youth culture and net culture: Online social practices (pp. 17-40). New York: Information Science Reference.

Malmberg, T. (1992). Time and space in human ecology. In R. M. Dubey (Ed.), Human ecology and environmental education (pp. 29-60). Allshabad, India: Chugh Publications.

Margitay-Becht, A. \& Herrera, D. R. (2012). Immersion and connectivity: How goaloriented fun can foster self-motivation. Presentation at the Conference Connectivity in the 21st Century, Salzburg, Austria.

Martinovic, D. \& Freiman, V. (2011). Child and youth development beyond age 6 Transitions to digitally literate adults. Presentation for Ministry of Child and Youth Services, Toronto, ON, Feb 11.

McAndrew, T. F. \& Jeong, S. H. (2012). Who does what on Facebook? Age, sex, and relationship status as predictors of Facebook use. Computers in Human Behavior, 28(6), 2359-2365.

McLachlan, J. S., Hellmann, J. J., \& Schwartz, M. W. (2007). A framework for debate of assisted migration in an era of climate change. Conservation Biology, 21(2), 297-302.

Nadkarni, A. \& Hofmann, S. G. (2011). Why do people use Facebook? Personality and Individual Differences, 52(3), 243-249.

Oblinger, D. \& Oblinger, J. (2005). Is it age or IT: First steps toward understanding the Net generation. In D. G. Oblinger and J. L. Oblinger (Eds.), Educating the Net Generation (pp. 2.1-2.2). Boulder, CO: Educause.

Oblinger, D. (2008). Growing up with Google: What it means to education. Emerging Technologies for Learning, 3(1), 11-29.

O'Brien, C. (2013). Who is teaching us about sustainable happiness and well-being? Health, Culture and Society, 5(1), 294-307.

Paillé, P. \& Mucchielli, A. (2008). L'analyse qualitative en sciences humaines et sociales. [Qualitative analysis in the social sciences] Paris: Armand Colin.

Pletka, B. (2007). Educating the net generation. Santa Monica, CA: Santa Monica Press. 
Proshansky, H. M., Fabian, A. K., \& Kaminoff, R. (1983). Place identity. Journal of Environmental Psychology, 3, 57-83.

Pruneau, D. (1995). Conception et expérimentation d'un processus de formation en cours d'emploi destiné à inciter les enseignants du préscolaire et du primaire à agir en éducation relative à l'environnement. [Education designed to encourage preschool and primary school teachers to act in environmental education] Doctoral thesis, Quebec: Université Laval.

Pruneau, D., Gravel, H., \& Ouattara, I. (2002). Les relations que les adolescents entretiennent avec leur environnement. Revue des sciences de l'éducation. [The relationship that teens have with their environment]. 28(3), 565-586.

Puk, T., \& Stibbards, A. (2010). Ecological concept development of pre-service teacher candidates: Opaque empty shells. International Journal of Environmental \& Science Education, 5(4), 461-476.

Register, R. (2006). EcoCities: Rebuilding cities in balance with nature. Gabriola Island: New Society Publishers.

Rollero, C. \& De Piccoli, N. (2010). Place attachment, identification and environment perception: An empirical study. Journal of Environmental Psychology, 30, 198-205.

Seidman, G. (2013). Self-presentation and belonging on Facebook: How personality influences social media use and motivations. Personality and Individual Differences, 54(3), 402-407.

Tapscott, D. (1999). Educating the Net generation. Educational Leadership, 56(5), 6-11.

Thomashow, M. (1995). Ecological identity: Becoming a reflective environmentalist. Cambridge, Mass: MIT Press.

Tosun, P. L. (2012). Motives for Facebook use and expressing "true self" on the internet. Computers in Human Behavior, 28(4), 1510-1526.

Yang, C. \& Brown, B. B. (2013). Motives for using Facebook, patterns of Facebook activities, and late adolescents' social adjustment to college. Journal of Youth and Adolescence, 42(3), 403-416.

Zecha, S. (2013). Significant influences on nature experiences: A comparative study of Southern German and Northern Spanish Pupils Aged 14 and 15. Discourse and Communication for Sustainable Education, 4, 23-42.

Correspondence concerning this article should be addressed to Diane Pruneau, University de Moncton, Canada. Email: diane.pruneau@umoncton.ca 